Abstract

\title{
Integration and Synchronization of Different Sensors for the Positioning of Moving Vehicles ${ }^{+}$
}

\section{Paul Rawiel}

Centre for Geodesy and Applied Informatics, University of Applied Sciences Stuttgart, 70174 Stuttgart, Germany; paul.rawiel@hft-stuttgart.de

+ Presented at the 5th International Symposium on Sensor Science (I3S 2017), Barcelona, Spain, 27-29 September 2017.

Published: 6 December 2017

For intelligent mobility concepts in growing urban environments, positioning of cars and generally moving objects is a fundamental prerequisite. Global Navigation Satellite Systems (GNSS) are commonly used for this purpose, but especially in urban environments under certain conditions they offer limited accuracy due to buildings, tunnels etc., that can deviate or mask the satellite signals. The installation of other motion sensors inside the vehicle can be used to describe the movement of the cars independently of GNSS. This conforms to the concept of Dead Reckoning (DR). Both systems (GNSS and DR) can be integrated and prepared to work together since they complement their respective weaknesses efficiently. In this presentation, a method to integrate different sensors (gyroscope, altimeter, accelerometer and wheel-ticks) and GNSS is developed. Extended Kalman Filter (EKF) is the base of calculations to perform data integration.

Several driving tests are realized to check the performance of the models. The results show that the developed system is able to improve GNSS positions and even fully substitute this system, e.g., in tunnels, where no GNSS signal is available, as long as this situation is not prolonged too much in time.

Conflicts of Interest: The authors declare no conflict of interest.

(C) 2017 by the authors. Licensee MDPI, Basel, Switzerland. This article is an open access article distributed under the terms and conditions of the Creative Commons Attribution (CC BY) license (http://creativecommons.org/licenses/by/4.0/). 